\title{
Towards Online Social Support for Former Military Personnel
}

\author{
Morten Kringelbach, Hugh McManners, Christine Parsons \\ Scars of War Foundation, \\ Queens College, Oxford University \\ $\{M k ; h m ;$ cep\}@scarsofwarfoundation.org
}

\begin{abstract}
The Armed Forces comprise a series of tight-knit communities sharing values and experiences, which provide a complete social and work-life network. Leaving the Forces is a significant life event, which in some people can lead to psychological and social problems, especially for younger members, those with existing mental disorders, and those who may be developing combat-related psychological conditions. We are examining the extent to which a dedicated online network constructed to reflect military social groupings might counter this, and provide connectivity between former comrades, plus a very wide range of useful information, from job seeking and family advice, to counselling and therapy. There are some $4.8 \mathrm{~m}$ ex-Service personnel in the UK (McManus, Meltzer Brugha, Bebbington and Jenkins 2007,).
\end{abstract}

UK Armed Forces, Combat-related PTSD, mTBI, Resettlement, Online Social Community

\section{INTRODUCTION}

When people leave the Armed Forces, they must make a rapid switch into the very different values of civilian life. Particularly if they can't find a job, the feelings of failure can lead to a downward spiral of psychological and accompanying social problems.

This phenomenon is most apparent in young soldiers who leave before completing their engagements (Kapur, While, Blatchley, Bray and Harrison 2009), and is also common with those who leave suffering from mental health and psychological problems - often as a result of their combat experiences.

The Scars of War Foundation is examining the possibilities of establishing an on-line community constructed with the same characteristics of rank, exclusive, closed units, membership forums, specific connectivity and communications as those of the real military world. This will be called "Re-Org.Net ${ }^{\mathrm{TM}}$ "

The underlying purpose of the Re-Org.Net online community would be to keep in touch with former comrades, prevent isolation, and get help to those who need it. Military people are highly sociable, but can be intolerant of those who cannot cope, attaching stigma to mental problems. This would prevent many from joining a social network that was overtly intended to help people with mental problems. The social network's must therefore be regarded as the online extension of the real military world.

\section{SCALE OF THE PROBLEMS}

UK data on the incidence of psychological problems and $\mathrm{mTBI}$ in the military is limited, and at variance with more extensive USA statistics. A large survey of US combat infantry deployed in Iraq (Hoge, McGurk, Thomas, Cox, Engel and Castro 2008) reported a prevalence of almost $15 \%$ with $\mathrm{mTBI}$, and $17 \%$ with post-traumatic stress disorder (PTSD) (Hoge and Castro 2004). 
UK military personnel who deployed to the 2003 Iraq war suffered 4\% PTSD compared to $13 \%$ in US military personnel. (Matthew Hotopf, Hull, Fear, Browne, Horn, Iversen, Jones, Murphy, Bland, Earnshaw, Greenberg, Hacker Hughes, Tate, Rona, 2006). This paper was challenged (Hoge and Castro Lancet 2006), showing that once the frequency and intensity of combat were taken into consideration, PTSD rates were very similar.

A British post-Falklands War study of the battle-hardened 2 Para said that $26 \%$ had the complete PTSD disorder, with $50 \%$ reporting two or more symptoms (O'Brien and Hughes 1991). 31\% of Vietnam vets suffer lifetime PTSD, 22\% of Falklands vets, and more than $50 \%$ of UK Gulf War body handlers had PTSD nine months after the war (Knapp, McCrone and Corkhill 2003).

Alcohol misuse and common mental disorders especially depression are more of a problem in the serving UK military, problem rather than PTSD (Fear, Jones et al, Lancet, May 2010).

Those with poor mental health are more likely to leave the Forces, are more likely to be socially excluded, and are a vulnerable group (Iversen, Nikolaou, Greenberg, Unwin, Hull, Hotopf, Dandeker, Ross and Wessely 2005).

UK soldiers suffering from PTSD would seem likely to range upwards from $4 \%$. If the higher USA figures prove to be more indicative of the outcome in the longer term, figures will be even higher.

In addition, $19.7 \%$ suffer common mental disorders, and $13 \%$ alcohol misuse (KCMHR 2010). This does not take into account the normal rates of psychological / mental illness that may be unrelated to military service also associated with this population.

It should be noted that one of the desired effects of Re-Org.Net's online social community is to reduce the 13 year help- seeking delay period. This in itself will reduce the numbers requiring long-term care. PTSD is thought more likely to affect women than men. (Breslau; Davis; Andreski; Peterson; Schultz 1997), and in differing ways. Increasing numbers of women are now serving, which was a novel feature of the Iraq and Afghan campaigns. Increasing numbers of female veterans with PTSD may emerge as a specific problem.

Some $10 \%$ of the total UK prison population of 86,500 are said to be exForces suffering from service-related psychological conditions, mainly imprisoned for violent crimes. Home Office documentation makes it impossible to verify this figure. Treadwell (2010) says the figures of $6 \%$ in 2004 have been revised upwards.

\section{NETWORK}

The aims of Re-Org.net are multifaceted, but must above all be regarded as a vibrant community in its own right.

BigWhite Wall http://www.bigwhitewall.com a site dealing with mental health problems, is offered free for veterans or members of the Armed Forces. Most Service people very strongly resist admitting to such problems because it will adversely affect their career (Greenberg, Military Medicine, Sept 2007). Those driven to seek help with Big White Wall are likely to have done so anyway, at which critical point they need specifically Forces-orientated treatment and help (Britt, Greene-Shortridge, Castro, 2007).

The principal aims of Re-Org.Net are:

- To provide a virtual community for serving and ex-Servicemen and women.

- giving access to others who may be able to help in a post-military situation.

- including employment opportunities 
- connect with people experiencing problems.

- easy access to suitably qualified therapists.

\section{APPROACH}

The website is intended to have a number of features, each with its own specific aim: a job centre, forums at each level of the hierarchy which can develop according to members' wishes (they might decide to have the following: 'officers mess', 'sergeants mess', 'NAAFI bar', coffee shop, Thrift Shop, wives club - reflecting the places where people meet in a real military unit. The names vary according to Service and regiment.). These will exist within a multitude of self-creating, member-only groupings based on military units and those who were together on specific military operations. There will also be links to welfare organisations like SAAFA, the Royal British Legion, The Soldiers Charity, Combat Stress and so on; and to therapists, with the use of geographical location services to help connect people - especially to potential therapists.

Funding of this will be a serious issue. The Freemium / sponsored route looks like the only option, although it is hoped that once established, the site may generate enough revenue to be self-sustaining.

A key feature will be places where people can reminisce, as informal and low-key therapy.

\section{THE PROBLEMS BEING ADDRESSED}

When a formerly well-integrated person leaves the Forces they may suffer from identity loss, which may be exacerbated by isolation (Thoits, 1983). They are however less likely to seek help as they feel able to endure the hardships of the street, and elevate the perceived shame of their situation (Johnsen, Jones and Rugg 2008).

Re-Org.Net seeks to reduce isolation through continued socialisation with former military colleagues, identifying potential problem cases earlier, preventing their decline to the level of becoming demanding and expensive welfare cases. The incorporation of organisations like the Soldiers, Sailors and Air Force Institute (SAAFA) and the Royal British Legion (RBL) into the network will be developed to achieve the earliest possible intervention.

Specific treatment for ex-Service people with combat-related psychological problems can be difficult to find within the NHS. Combat veterans treated for PTSD with their fellows in US Veterans Affairs Hospitals fared better than $66 \%$ of patients in control conditions (Goodson, Helstrom, Halpern, Ferenschak, Gillihan, Powers 2011),

With combat-related PTSD, therapists may need to use specialised intensive versions of CBT and EMDR, and SSRI's may not be as effective as with PTSD arising from within the wider community (McCrone, Knapp and Cawkill 2003). Therapists may also require additional supervision and support when treating combat-related disorders (Sexton 1999). Linking veterans up with therapists who are trained and experienced in dealing with combat related problems is vital. It is currently difficult for veterans to find suitable therapists.

\section{A REQUEST FOR ADVICE}

This is a new area for us. We're looking for ideas. If a social network can be designed to reflect military society - while also being flexible enough allow selfmodification, we'd have created a community that could aggregate its efforts and help itself.

\section{REFERENCES}


Breslau; Davis; Andreski; Peterson; Schultz, (1997) Sex Differences in Posttraumatic Stress Disorder, General Psychiatry November 1997

Britt, Thomas W.; Greene-Shortridge, Tiffany M.; Castro, Carl Andrew (2007), The Stigma of Mental Health Problems in the Military, Military Medicine, Volume 172, Number 2, February 2007, pp. 157161(5)

Fear, M Jones, Murphy, Iversen, Coker, Machell, Sundin, Woodhead, N Jones, Greenberg, Landau, Dandeker, Rona, Hotopf and Wessely. (2010) 'What are the consequences of deployment to Iraq and Afghanistan on the mental health of the UK Armed Forces? A cohort study,' Lancet May 2010.

Goodson J, Helstrom A, Halpern JM, Ferenschak MP, Gillihan SJ, Powers MB, (2011) Philadelphia VAMC, Treatment of posttraumatic stress disorder in U.S. combat veterans: a meta-analytic review. Psychol Rep. 2011 Oct; 109 (2): 573-99.

Hoge and Castro, (2006) "Post-traumatic stress disorder in UK and US forces deployed to Iraq." The Lancet, Volume 368, Issue 9538, Page 837, 2 September

Hoge, McGurk, Thomas, Cox, Engel and Castro, (2008) Mild Traumatic Brain Injury in U.S. Soldiers Returning from Iraq, New England Journal of Medicine

Hoge, Castro, Messer, McGurk, Cotting and Koffman, (2004) Combat duty in Iraq and Afghanistan, mental health problems, and barriers to care. (2004) N Engl J Med. ; 35113-22

Hotopf, Hull, Fear, Browne, Horn, Iversen, Jones, Murphy, Bland, Earnshaw, Greenberg, Hacker Hughes, Tate, Rona. (2006) "The health of UK military personnel who deployed to the 2003 Iraq war: a cohort study." The Lancet, Volume 367, Issue 9524, Pages 1731 1741, 27 May
Iversen, Nikolaou, Greenberg, Unwin, Hull, Hotopf, Dandeker, Ross and Wessely (2005). What happens to British veterans when they leave the armed forces? European Journal of Public Health Volume 15, Issue 22005

Iversen, van Staden, Hacker Hughes, Browne, Hull, Hall, Greenberg, Rona, Hotopf, Wessely and Fear. (2009) "The prevalence of common mental disorders and PTSD in the UK military: using data from a clinical interview-based study." BMC Psychiatry.

Johnsen, Jones and Rugg, (2008) The Experiences of Homeless Ex-Service Personnel in London, Centre for Housing Policy, University of York.

Kapur, While, Blatchley, Bray and Harrison, (2009) "Suicide after Leaving the UK Armed Forces - a Cohort Study".PLoS Medicine March.

McCrone, Knap, and Cawkill, Kings College Health Economics Study 2003

McCrone, Knapp and Cawkill (2003), Posttraumatic Stress Disorder (PTSD) in the Armed Forces: health economic considerations. Journal of Traumatic Stress 16 519-522

McManus, Meltzer, Brugha, Bebbington and Jenkins, (2007) Adult Psychiatric Morbidity Study, NHS Information Centre

O'Brien S and Hughes S J, (1991) Symptoms of post-traumatic stress disorder in Falklands veterans five years after the conflict. The British Journal of Psychiatry 159: 135-141

Sexton L, Vicarious traumatisation of counsellors and effects on their workplaces. (1999) British Journal of Guidance \& Counselling Volume 27, Issue 3,

Treadwell (2010), "More than casualties of war: Ex-Military Personnel in the Criminal Justice System" The Howard Journal Vol 49 No 1 Feb 2010 